\title{
Jorge Luis Borges traductor de Die Verwand- lung (Fechas, textos, conjeturas)
}

\author{
Juan FLÓ \\ Universidad de la República (Montevideo, Uruguay)
}

\begin{abstract}
RESUMEN
Este trabajo se propone analizar la discutible autenticidad de la traducción de La metamorfosis de Kafka, publicada en 1933 por la Revista de Occidente (Madrid), sin nombre de autor, y publicada nuevamente en Buenos Aires en 1938 por la editorial Losada atribuyendo esta traducción a Jorge Luis Borges (y muchísimas veces reeditada, hasta el presente, con la misma atribución). Puesto que no disponemos de ningún documento absolutamente probatorio que sustente una conclusión definitiva, y cómo es posible incluir entre esos documentos insuficientes las declaraciones de Borges, se intenta interrogar aquí a los más diversos indicios -entre otros el concepto de traducción sustentado por Borges- y leerlos desde una perspectiva que no olvide los juegos borgianos.
\end{abstract}

Palabras claves: Borges, Kafka, Die verwandlung, La metamorfosis, traducción.

\section{Jorge Luis Borges translator of Die Verwandlung (Dates, texts, conjectures)}

\begin{abstract}
This paper seeks to shed light on the debatable authenticity of the translation of Kafka`s Metamorphosis, published -without author- in the Revista de Occidente (Madrid, 1933). This same translation was published again in Buenos Aires, in 1938, by Losada Publishing House, and in this opportunity it was attributed to Jorge Luis Borges. It was afterwards republished several times with the same attribution. Due to the fact that there are several documents regarding this issue but none of them leads to a definitive conclusion and at the same time among those unsufficient documents we can include Borges`own statements, we try here to debate on the most diverse evidences and read them form a perspective that takes into account borgians games and Borges' concept of translation itself.
\end{abstract}

Key words: Borges, Kafka, Die verwandlung, La metamorfosis, translation.

\section{$¿$ Borges traductor?}

El 17 de noviembre de 1912 Kafka dirigió una carta a Felice en la que le cuenta que tiene que escribir una pequeña historia que se le ha ocurrido cuando estaba en su lecho, desolado, y que lo acosa desde su interior. El 18 de noviembre en una nueva carta le dice que es una historia en la que tiene un ansia sin límites de volcarse. El 24 de noviembre, en la misma correspondencia, le informa que es una historia 
con la que no está, en términos generales, descontento pero que es asqueante de un modo ilimitado. En carta del 6-7 de diciembre le comunica que la historia está terminada pero no está feliz con el final que le ha dado (aunque no sabemos si es ese el que admitió como definitivo). ${ }^{1}$

Mucho tiempo después, en 1968, Canetti dirá en su agudo análisis de la correspondencia de Kafka con Felice, sólo publicada en 1967, que La metamorfosis es una de las pocas obras maestras y perfectas de este siglo. ${ }^{2}$ Antes, en 1950, Edmund Wilson, en medio del naciente entusiasmo de la crítica norteamericana por la obra de Kafka, aventuró "a dissenting opinion”, pero a pesar de todo consideró a $L a$ metamorfosis uno de los más importantes textos de Kafka, y a este como el autor de algunos relatos "absolutely first-rate". ${ }^{3}$

Escrita en unos veinte días, la realización de La metamorfosis no ocupó de manera exclusiva el tiempo de trabajo narrativo de Kafka. Ese tiempo estuvo ocupado también por una correspondencia que refleja las obsesiones recurrentes de este en relación con Felice. Una correspondencia que es más extensa que el relato. (He hecho el cálculo: llevadas a páginas de igual densidad de texto con un formato en el cual La metamorfosis ocupara 100 páginas, la correspondencia con Felice de esos dieciocho días ocuparía unas 140 páginas). Ese inmenso trabajo de escritura simultánea creo que incita a realizar, y permite suponer fructífera, una minuciosa colación de los dos textos. Quizá entonces podríamos ver mejor en qué medida la escritura está unida en Kafka a ciertas experiencias, acontecimientos y funciones, y en qué medida es un producto construido como algo autónomo. Y, a partir de entonces, precisar la distancia que mantiene con el expresionismo y con la vanguardia en general.

En 1915 se publica La metamorfosis. El manuscrito había sido ofrecido a la revista Die Neue Rundschau, que lo aceptó para su publicación. Pero hubo dilaciones y también la exigencia de que su autor redujera sensiblemente la extensión del relato, por lo cual terminó siendo publicado primero en Die Weisen Blatter y ense-

\footnotetext{
${ }^{1}$ Franz Kafka. Briefe an Felice, Frankfort an Main: Fisher Verlag, 1967. Los pasajes indicados son: [...] und ich bin auch im allgemeinen mit ihr nicht unzufrieden, aber eklhaft ist sie grenzenlos (17/XI/ 1912), p. 102. [...] mit einem unbegrenzten Verlangen, mich in sie auszugiessen (18/Xl/1912), p. 105. [...] und eine kleine Geschichte niederschreiben werde, die mir in dem Jammer im Bett eigefallen ist und mich innerlichst bedängt (24.Xl.1912) p. 117. Libste, also ihöre, meine keine Geschichte ist beendet, nur macht mich der heutige Schluss gar nicht froh, er hätte schon besser sein dürfen, das ist kein Zweifel. (67/XII/1912), p. 163.

${ }^{2}$ Elías Canetti, "El otro proceso. Las cartas de Kafka a Felice”, en La conciencia de las palabras. México: Fondo de Cultura Económica, 1981 [1974].

${ }^{3}$ Edmund Wilson, “A Dissenting Opinion on Kafka”, en Classics and Commercials. New York: Farrar, Strauss \& Co. 1950.
} 
guida bajo forma de libro, a finales de ese año (aunque la portada, con un dibujo más bien expresionista y de pathos muy poco kafkiano, indica el año $1916 .{ }^{4}$

En 1915 Borges hacía un año que estaba estudiando en el Collège de Genève, que fundara Calvino. Había llegado a Suiza con su familia en 1914, donde permanecería con ella hasta 1919. En esos años ocurre el primer tramo de una intersección memorable entre dos obras y dos autores muy disímiles, pero muy congeniales. Una obra como la de Kafka que muestra la impotencia de la racionalidad obsesiva (¿a pesar de ser obsesiva o por serlo?) y otra que se permite el desdén juvenil y pendenciero propio del talento. Una obra que sabe de la artesanía pero nunca de su uso lúdico e ignora a la autorreferencialidad que caracteriza a las obras de la vanguardia en que el arte es el tema del arte y otra que, si exceptuamos la poesía, es literatura antes que nada a partir de la literatura, obra maestra de la ironía y la litote, que juega con las ideas, con las citas y también con las referencias falsamente documentales o biográficas.

Un autor que vive en un lugar del mundo fragmentado en culturas y nacionalidades diferentes y en víspera de su derrumbe; un escritor cuyas raíces no lo atan a ninguno de los lenguajes que conviven en su entorno aunque posea una gran maestría en uno de ellos, y que no tiene un lugar propio que no es asumido en su cuerpo ni en su familia ni en ninguna de las comunidades de las que es y no es parte. Otro autor que pertenece también a un mundo periférico pero próspero y jactancioso, alguien que no solamente reivindica la forma nacional de un lenguaje que hablan los hombres de veinte países, sino que además posee por tradición la lengua del Imperio y que ha recibido por herencia familiar una memoria levemente heroica que abarca toda la historia de su joven nación.

Es cierto que podemos presumir que las obras y las personalidades de los dos escritores tienen en común cierto núcleo duro, un núcleo que nos permite, a pesar de todas las diferencias, considerarlos escritores congeniales y que explica la atracción que el primero ejerció sobre Borges, así como la eficacia de este último para hacernos ver a la luz de su propia narrativa y de su visión crítica la obra de Kafka. Quizá ese núcleo duro radica en que los dos -seguramente entendiendo cosas distintaspodrían decir, como lo hizo uno de ellos, que les aburre todo lo que no es literatura.

Tratemos de precisar el momento del encuentro. Allí, en Ginebra, mientras hacía sus estudios regulares, Borges emprendió, sin maestro, el estudio del alemán, aven-

\footnotetext{
${ }^{4}$ Estos datos sobre la historia de la publicación provienen de Hartmut Binder. Kafka und Die neue Rundschau, en Jahrbuch der deutsche Schillergesellschaft, XII. Stuttgart: A. Króner, 1968, pp. 94-111. Y también de las notas a los items 72 al 75 del catálogo de la exposición Franz Kafka 1883-1924, organizada por el Bundesministeriums für Auswärtige Angelegenheiten, editado por Zirkular, Sondernsummer, 3, Viena, 1983.
} 
tura a la cual se refirió luego muchas veces de manera detallada. ${ }^{5}$ Según Emir Rodríguez Monegal, en 1918 Borges no había oído hablar de Kafka. ${ }^{6}$ Es una afirmación seguramente equivocada. El propio Borges me comunicó personalmente que había leído algo de Kafka en 1917 en la revista Die Action y en declaraciones a Clarín, en 1983, duda acerca de si descubrió a Kafka en Die Action (leo así ese nombre; quien transcribió la grabación no comprendió el nombre de la revista y lo volvió irreconocible) o en Der Sturm. Como sea, afirma sin vacilación que leyó en 1917 una página de Kafka que le "llamó la atención, una página muy extraña, muy tranquila, no puedo precisar exactamente todos los detalles, pero era muy extraña". 7 Esto no es para nada inverosímil porque nadie discute la familiaridad de Borges con la literatura alemana de vanguardia a partir de su estadía en Suiza. El propio Rodríguez Monegal reconoce que, en Lugano, donde Borges pasó su último año en Suiza, estuvo más aislado que en Ginebra y recurrió al alemán para llenar el vacío de su vida literaria. Recuerda también Monegal (aunque sin proporcionar el dato bibliográfico) que en 1921 Borges publicó en España una reseña sobre una antología de la poesía expresionista alemana de la que era en ese momento conocedor y admirador. ${ }^{8}$ Pero si no queremos conservar ninguna duda sobre la atención que prestó al expresionismo alemán, y sin necesidad de confiar en la memoria del escritor ni en fuentes imprecisas, alcanza indicar las otras publicaciones en las cuales se refiere a ese movimiento. Borges publicó su primer artículo sobre el expresionismo en la revista Grecia en $1920,{ }^{9}$ otro, tres meses después, en la misma revista sobre el poeta

${ }^{5}$ Por ejemplo en Bienek. Coloquio con Jorge Luis Borges, en Humboldt, $\mathrm{n}^{\circ}$ 24, 1965. También en Jorge Luis Borges. Autobiographical Notes (en colaboración con Norman Thomas Di Giovanni), en The New Yorker, New York, n 19, setiembre 1970.

${ }^{6}$ Emir Rodríguez Monegal. Borges, una biografía literaria. México: Fondo de Cultura Económica, 1987, p. 122. (Traducción de Homero Alsina Thevenet) [1978].

${ }^{7}$ Declaraciones de Jorge Luis Borges en Clarín, Buenos Aires, 30 de junio de 1983.

${ }^{8}$ E. Rodríguez Monegal, op. cit. p. 131. Se trata de un artículo titulado publicado en Ultra, Madrid, Año I, N 16, 20 de octubre de 1921. Cuando Rodríguez Monegal publicó su antecitada biografía, no se habían recopilado los textos de ese período -lo que sólo ocurrió, insólitamente con la edición francesa de las obras borgesianas (Oeuvres de Jorge Luis Borges, T. I, publicadas en la colección La Pléiade en 1993 como resultado del ingente trabajo de Jean-Pierre Bernès) en las que se basan, confesándolo a medias, los Textos recobrados de Borges. Buenos Aires, Emecé, 1997. Que en este caso no proporcione los datos bibliográficos de rigor hacen suponer que Rodríguez Monegal, en general tan minucioso en cuanto a la documentación, aparentemente no tenía interés en facilitar el acceso a esos textos entonces secretos.

9 “Lírica expresionista: síntesis”, en Grecia, Sevilla, Año 3, n 47, 1 de agosto de 1920. 
Willhelm Klemm, ${ }^{10}$ un tercero que es la reseña publicada en 1921 en la revista Ultra, que menciona Rodríguez Monegal, y un cuarto en la revista Inicial en 1923 luego recogido en su primer y luego renegado libro de ensayos Inquisiciones-, en el cual no sólo se muestra la familiaridad del escritor con la literatura de vanguardia en lengua alemana, sino que también expresa su simpatía, tanto en su juicio ("En los mejores poemas expresionistas hay la viviente imperfección de un motín”) como quizá más todavía en su interés por traducirlos ("soy yo el culpable de la españolización de los versos") con una literalidad que no mitiga en absoluto las libertades en el uso del lenguaje y la ultranza de las imágenes. ${ }^{11}$ En 1926 en una nota autobiográfica hasta hace poco no muy conocida, le da un lugar, a pesar de que se trata de un texto brevísimo, a sus traducciones de los poetas expresionistas alemanes. ${ }^{12} \mathrm{Y}$ en 1970 recordará esas traducciones hechas por él en España como las primeras y quizá las únicas traducciones al español de poetas expresionistas, y dice que sigue creyendo que el expresionismo es superior a otras escuelas contemporáneas como el imaginismo, el cubismo, el futurismo, el surrealismo. ${ }^{13}$

Los libros de Kafka, por otra parte, no eran volúmenes desconocidos y provincianos que estuvieran fuera del circuito de la literatura alemana de vanguardia, sino todo lo contrario. Aunque publicados en tiradas reducidas, lo fueron en una editorial prestigiosa que difundía a los nuevos poetas (Rowohlt en el caso de su primer plaquette, Betrachtung, y luego en la del exsocio de este, Kurt Wolff ), por lo cual su breve obra de esos años no fue imperceptible. Tanto es así que La metamorfosis fue "premiada" de una manera singular ya que el destinatario del premio Fontane, Karl Sternheim, renunció, tras algunos manejos editoriales, a percibir el monto del premio en beneficio de Kafka. Y hay que señalar que dicho premio era no sólo honorífico sino que tenía una estimable significación económica. Por otra parte, si repasamos la literatura crítica que se produce en lengua alemana entre 1915 y 1920 encontramos un buen número de ensayos y notas que mencionan a Kafka escritas por autores significativos de la vanguardia como Pinthus y Edschmidt, entre otros. ${ }^{14}$

10 “Lírica expresionista: Wilhelm Klemm”, en Grecia, Sevilla, Año 3, no 50, $1^{\circ}$ de noviembre de 1920.

${ }^{11}$ Jorge Luis Borges. Inquisiciones. Buenos Aires: Proa, 1925, pp. 146-152.

${ }^{12}$ Se trata de un texto incluido en la noticia correspondiente a Borges de la Antología de la poesía argentina moderna, ordenada por Julio Noé, Buenos Aires: Ed. Nosotros, 1926.

${ }^{13}$ Autobiographical Notes, op. cit.

${ }^{14}$ En Paul Raabe (ed.). Der Kampf um eine literarische Bewegung. Munich, Deutsche: Taschenbuch Verlag, 1965. Pueden encontrarse referencias a Kafka en artículos de Pinthus (19l5), p. 76; Herwig (1916), p. 81; Edschmid (1918) p. 89; Schickele (1920) p. 177. En Paolo Chiarini. Caos e Geometría: Per un regesto delle poetiche espressioniste. Firenze: La Nuova Italia, 1964, encontramos referencias a Kafka en los resúmenes de los artículos de Krell (1919), p. 109, Mierendoff (1920), p. 109, Edschmid (1920) p. 92 
Es por lo tanto digno de todo crédito lo que Borges ha reiterado acerca de su precoz conocimiento de Kafka. Aún sin esas declaraciones, se hubiese podido conjeturar que no sólo es posible sino muy probable que Borges haya leído algo de Kafka muy tempranamente y si eso fue así es inverosímil que se le hubiese escapado su singularidad, por más que en algún momento reconoce haberlo conocido tempranamente, aunque se culpa de haber sido tan insensible que le pareció un poco anodino. $^{15}$

Todo lo anterior vuelve algo extraña una afirmación que aparece en el libro publicado por el Centre Georges Pompidou en ocasión de una notable exposición denominada "Le siècle de Kafka", que se exhibió en 1984: "Borges a decouvert Kafka en traduction anglaise a la fin des années trente, au moment ou pour gagner sa vie, il travaille comme employé dans une bibliothèque municipale". ${ }^{16}$ Esta afirmación es simplemente la amplificación de algunos enunciados sin fundamento formulados por Rodríguez Monegal: "en aquellos años (se refiere a los años de su trabajo en una biblioteca municipal a partir de 1937) Borges había comenzado a leer a Kafka”. ${ }^{17}$ Esta aseveración unida a la que he citado antes, también de Emir Rodríguez Monegal, en el sentido de que en 1918 Borges no había oído hablar de Kafka, es sin duda la fuente del error de la publicación del Centre Pompidou.

En 1921 Borges retorna a Buenos Aires con su familia después de haber pasado unos dos años en España. Son muy conocidos los fuertes vínculos que establece en esa estadía. En 1923 vuelve a España y regresa a Buenos Aires al año siguiente. En ese período sus contactos con la Revista de Occidente quedan documentados por algunos textos. En el número de abril-junio de 1924 de dicha revista Ramón Gómez de la Serna reseñó Fervor de Buenos Aires, y en el de noviembre de 1924 el propio Borges publicó un artículo (Menoscabo y grandeza de Quevedo) recogido luego en Inquisiciones.

En 1925 aparece, también en la Revista de Occidente, la traducción al español de La metamorfosis, una parte en el número de junio de 1925 (mes del primer aniversario de la muerte de Kafka, hecho que allí no se invoca), y la parte final en el número de julio del mismo año. Esa traducción, como era norma en la revista, aparece sin nombre de autor y no parece posible rastrear actualmente esa autoría apelando a la memoria o a los documentos del entorno de la revista, entre otras razones porque sus archivos fueron destruidos. Efectivamente, esa tarea ya le resultó imposible en 1972 a Eveline López Campillo quien, de todos modos, aventura la hipótesis de que el autor de la traducción pudo ser R. M. Tenreiro, quien publicó una reseña sobre El proceso y El castillo en el número de junio de 1927 de Revista

${ }^{15}$ En Diálogos Jorge Luis Borges-Osvaldo Ferrari. Barcelona: Seix-Barral, 1992, p. 71.

${ }^{16}$ Le siècle de Kafka. Paris: Centre Georges Pompidou, 1984.

${ }^{17}$ E. Rodríguez Monegal, op. cit., p. 283. 
de Occidente. ${ }^{18}$ La hipótesis no se sostiene a la luz de la reticencia con la que Tenreiro expresa su opinión sobre esas novelas y, de alguna manera, sobre la escritura de Kafka en general: "hay un tremendo contraste -y no sé si feliz- entre el procedimiento realista con que están pintados los sucesivos cuadros y el recóndito y enigmático fundamento ideal que debe prestarle unidad a todos ellos”, dice Tenreiro con referencia a las novelas de Kafka que considera en su nota. ${ }^{19}$ Esa dubitativa recepción por parte del crítico de un rasgo esencial de la narrativa de Kafka vuelve poco verosímil que sea el responsable de la publicación hecha dos años antes, a no ser que la tarea le fuera impuesta y, en consecuencia, el "descubridor" de Kafka hubiese sido otro, lo que no parece probable.

En 1945 la Editorial Revista de Occidente publica la misma traducción, otra vez sin nombre de autor. Sin embargo, según Cristina Pestaña Castro se le atribuye a Galo Sáez en algunas bibliografías de las que no ofrece información precisa. ${ }^{20} \mathrm{El}$ único lugar en el que he podido ver esa atribución es en una edición de La metamorfosis traducida y prologada por Ángeles Camargo, pero en la que se asigna a ese traductor no el texto de la revista de 1925, sino el de la edición en forma de libro de 1945, sin detectar que la traducción es idéntica a la atribuida a Borges en 1938, traducción que cita como si fuese la primera. ${ }^{21}$ Lo más probable, en apariencia, es que se trate de una confusión puesto que Galo Sáez fue el impresor de la Revista de Occidente. De todos modos no me resigno a simplificar las cosas y cedo a la tentación de dejar una semilla de incertidumbre, puesto que la confusión se vuelve menos explicable si sabemos que Galo Sáez aún no era impresor de la revista cuando esta publica, en 1925, el relato de Kafka y el que figura como impresor de esos números es Rafael Caro Raggio. Sólo algún tiempo después Galo Sáez pasa a ser impresor de la revista, pero ya no es él, sino su viuda, la que figura como impresora en el colofón de la edición de La metamorfosis en forma de libro de 1945. La confusión se vuelve por lo tanto más inverosímil cuanto que en ninguna de las dos publicaciones de la traducción aparece, en sentido estricto, el nombre de Galo Sáez. Ni siquiera como impresor.

En fin, en 1999, Cecilia Pestaña Castro nos trasmite la vacilante hipótesis propuesta por el hijo de José Ortega y Gasset, para la que no aduce ningun elemento

${ }^{18}$ Eveline Lopez Campillo. La Revista de Occidente y la creación de minorías (19231936). Madrid: Taurus, 1972.

${ }^{19}$ R. M. Tenreiro, "Franz Kafka, Der Prozess. Das Schloss”, en Revista de Occidente, junio 1927, p. 387.

20 ¿Quién tradujo por primera vez La metamorfosis de Franz Kafka al castellano?, en Espéculo, Universidad Complutense de Madrid, № 11, 1999.

${ }^{21}$ Franz Kafka. La metamorfosis y otros relatos. Edc. y trad. de Ángeles Camargo Madrid: Cátedra, 1997. 
que le dé cierto asidero, de que la traducción podría ser de Margarita Nelken. ${ }^{22}$ Tal hipótesis, que solamente habla de una pura posibilidad, por otra parte colide con el hecho de que, exilada en México, colaboradora de Cuadernos Americanos -y seguramente mucho más al tanto de la producción editorial de Buenos Aires de lo que lo estaba el encerrado mundo de la España franquista, en el que la primera edición de Losada casi fue desconocida- no dejó ningún testimonio que haya circulado en el mundo intelectual del exilio español acerca de la autoría de la traducción y de la indebida apropiación de la que habría sido objeto.

La traducción de la Revista de Occidente es notable en más de un sentido. En primer lugar, es la primera traducción del relato a otra lengua. La traslación al francés, hecha por Viallatte, data de 1928 (y, siguiendo el modelo español sale en dos números de la Nouvelle Revue Française). La traducción al inglés de Lloyd aparece en 1937. Y si bien algunos textos de Kafka fueron traducidos al checo desde 1920 (por Milena Jesenska), y tengo noticia de una traducción de textos breves al holandés publicada en 1924 por el poeta expresionista belga (flamenco) André van Ostaijen, ${ }^{23}$ por lo que sé no se publicó en ninguna lengua traducción alguna de los relatos más extensos de Kafka que sea anterior a la de Revista de Occidente de La metamorfosis.

Esta prioridad mundial, que no he visto nunca suficientemente destacada, es notable por lo menos por dos razones. La primera es lo extraño que resulta el hecho de que, si exceptuamos la cultura alemana, haya sido en el mundo de lengua española donde estuviese la antena más sensible y enterada, capaz de percibir la importancia de un autor como Kafka. Para darse cuenta de la gran perspicacia que esto supuso, es un buen fondo contrastante el hecho de que Joyce, nueve años después, en 1936, ignoraba completamente a Kafka. Y tanto que, en una conversación con Beckett, confundió a F. Kafka con una traductora del Frankfurter Zeitung de igual apellido. ${ }^{24}$

El segundo hecho que vuelve notable dicha prioridad es que esa detección casi milagrosa no va acompañada de ningún "efecto Kafka” sobre la literatura de lengua española hasta una época muy posterior. Es notable que ni siquiera de modo retardado el "efecto K" se hiciera sentir en España, donde ocurrió, aparentemente, el más precoz reconocimiento de ese escritor. Salvo Borges, no hay ningún autor de nuestra lengua que, en la década de los años treinta, acuse el "efecto Kafka" de alguna manera, aunque sea bajo la forma de una revelación acerca de las posibilidades de la escritura, como cuenta García Márquez que le ocurrió a él muchos años

${ }^{22}$ C. Pestaña Castro, op. cit.

${ }^{23}$ Expressionism as a Literary International Phenomenon. Paris-Budapest: DidierAkademiai Kiadó, 1973, p. 239.

${ }^{24}$ Richard Ellman. James Joyce. New York/Oxford/Toronto: Oxford University Press, 1982, p. 702 ( $2^{\text {a }}$ ed. revisada). 
después: “Al ver que Gregorio Samsa podía despertarse una mañana convertido en un gigantesco escarabajo, me dije: "Yo no sabía que esto era posible hacerlo. Pero si es así, -escribir me interesa»”. ${ }^{25}$ Es cierto que podríamos suponer que algo parecido le ocurrió a Alejo Carpentier algunos años antes, aunque también su testimonio procede de los años cincuenta. En un artículo de su época caraqueña, Carpentier, después de citar el comienzo de La metamorfosis, y de afirmar que lo maravilloso es el elemento más permanente que ha nutrido la literatura a través de los siglos, atribuye a Kafka un rasgo que también encuentra en Apuleyo: "acepta lo maravilloso sin inmutarse". ${ }^{26}$ (Recordemos, por otra parte que Carpentier cita la traducción de la Revista de Occidente como "una primera traducción”, sin hacer referencia a su autor, lo que excluye que la considere obra de Borges o que la haya contejado con el texto publicado en 1938 en el que aparece dicha atribución. Esta ignorancia de Carpentier es significativa porque su temprano interés en Kafka está documentado por el hecho de que cuando era secretario de redacción de la fugaz revista Imán, que editó Elvira de Alvear en París, se publicó en ella un texto de Kafka, La sentencia, que es el tercer texto de Kafka que aparece en español). ${ }^{27}$

También es notable que, como veremos, esa procastinada fecundación en las literaturas hispánicas tenga, en cambio, su compensación en la literatura francesa precisamente a través de la traducción de la Revista de Occidente.

El parentesco entre Kafka y Henri Michaux ha sido señalado varias veces aunque, en algún caso, ha sido negada la influencia directa del primero. En un libro sobre la influencia de Kafka en la literatura francesa se lee:

Henri Michaux publie son premier livre en 1922. Des oeuvres importantes telles que Mes Proprietés, Ecuador, Un certain Plume et La Nuit remue paraissent en 1931; Kafka est encore peu connu en France. Michaux a trouvé son style des 1927 avec Qui je fus, un an avant que la première traduction de Kafka ne paraisse en France. L'on ne saurait donc parler d'influence, encore que, depuis, Michaux ait certainemente pratiqué l'oeuvre de Kafka. ${ }^{28}$

Sin embargo, el propio Michaux no se amparó en esa coartada y declaró haber leído a Kafka por primera vez en Revista de Occidente: “Le premier texte que j’ai lu

${ }^{25}$ Gabriel García Márquez. El olor de la guayaba. Conversaciones con Plinio Apuleyo Mendoza. Barcelona: Bruguera, 1982, p. 41.

${ }^{26}$ Alejo Carpentier, "Permanencia de lo maravilloso”, en El Nacional, Caracas, 10 de julio de 1954. Republicado en Eco, Bogotá, nº 223, Mayo de 1980.

${ }^{27}$ Imán, $\mathrm{n}^{\circ} 1$, abril de 1931. La traducción de La sentencia, de Kafka es de Arqueles Vela. Es de señalar que en el mismo número aparece un extracto de la novela Ecué-Yamba-O, de Carpentier.

${ }^{28}$ Maja Goth. Franz Kafka et les lettres françaises. Paris: Corti, 1956, p. 65. 
[de Kafka] est La métamorphose que j'ai du Iire en espágnol quelque temps aprés sa parution dans la Revista de Occidente de Ortega y Gasset”. ${ }^{29}$ Ese descubrimiento a través de la Revista de Occidente puede parecer extraño si no tenemos presentes algunos de los vínculos de Michaux. Voy, por lo tanto, a permitirme recordar la conocida red de vínculos personales e intelectuales que hacen que ese descubrimiento sea algo natural. En primer lugar la relación de Michaux con Jules Supervielle, iniciada en 1922 con el envío que Michaux le hace de sus Fables des origines, y que pronto se transformó en una fuerte amistad. En 1936 Supervielle y Michaux viajan juntos al Río de la Plata en ocasión de un congreso del PEN Club y Michaux permanece un tiempo en la estancia de los Supervielle en Uruguay. Sin duda el vínculo por excelencia entre los diversos actores de esta historia es Supervielle: él también publicó en los años veinte en la Revista de Occidente y mantuvo amistad con Fernando Vela, el secretario de la misma y con Borges. La relación con este último está documentada por los dos actores y se puede rastrear en algunos textos. A poco de terminada la Segunda guerra mundial, en un poema de 1946 publicado en Oublieuse memoire y titulado Champs Elysées, Supervielle menciona por sus nombres de pila a los poetas latinoamericanos que siente como dobles, desembarcados en América, de los poetas franceses, y en ese puñado de nombres figura Jorge Luis. Y fue Norah, la hermana de Jorge Luis, quien ilustró un libro de relatos de Supervielle traducidos al español incluido en la misma colección en la que la editorial Losada publicó La metamorfosis -edición sobre la que volveremos-. Por su parte, en 1941 Borges traducirá para la editorial Sur Un barbare en Asie, de Michaux. En 1960, en un homenaje que hace la revista Sur a Supervielle unos meses después de su muerte, Borges, no muy dado a necrológicas, escribe una nota en la que reconoce, en el que llama su amigo, el hábito del lenguaje propio del mito que pertenece "a la noche, a la niñez y a la iluminación de los sueños". ${ }^{30}$

La amistad común de Supervielle con Michaux y Borges debemos integrarla en el círculo más amplio del grupo formado alrededor de Valéry Larbaud, grupo integrado por los escritores de lengua inglesa y de lengua española que colaboraban junto con sus amigos franceses en sus revistas Commerce y Le Navire d'Argent, y que frecuentaban en París a las famosas libreras y editoras Sylvia Beach y Adrienne Monnier. Aunque Rodríguez Monegal ha dado una versión verosímil de las relaciones de Borges con Ricardo Güiraldes y su círculo, con mención expresa de Larbaud -versión en la que se señala la módica estima que como escritor le merece este último a Borges-, ${ }^{31}$ lo cierto es que Larbaud no ignoraba a Borges a quien cita en su Lettre a deux amis, dirigida a Güiraldes y Adelina, y publicada nada menos que en

${ }^{29}$ Cit. Robert Bréchon en Henri Michaux. Paris: Gallimard, 1959, p. 208.

30 Jorge Luis Borges, “Jules Supervielle”, en Sur, Buenos Aires, setiembre-octubre 1960.

${ }^{31}$ E. Rodríguez Monegal, op. cit., p. 171. 
Commerce, la revista en la que aparecen primicias de Joyce (y de Michaux, y de Supervielle). ${ }^{32}$

Esta red de vínculos no sólo vuelve natural que por los años 25 o 26 Michaux conozca a Kafka a través de la publicación madrileña, sino que también sugiere que ese texto debe haber sido comentado en los círculos a los que nos referimos, círculos a alguno de cuyos anillos Borges está integrado de manera conspicua.

Las traducciones pioneras de Kafka continúan en Revista de Occidente. En mayo de 1927 se da a conocer la traducción de Hungerkunstler con el título de Un artista del hambre. En noviembre de 1932, Erstes Leid con el título de Un artista del trapecio.

En 1938 la editorial Losada de Buenos Aires publica La metamorfosis. Se trata de un volumen que incluye también algunos textos breves y otros tres algo más extensos: La muralla china, Un artista del hambre, y Un artista trapecio. Si se compara esa traducción de La metamorfosis con la traducción anónima de la Revista de Occidente puede comprobarse que es la misma con muy pequeños cambios. También se corresponden palabra por palabra los textos de este volumen con las otras dos traducciones que he mencionado, publicadas en 1927 y 1932 por la Revista de Occidente. Pero en la edición de Losada esas traducciones no son anónimas sino que figura el nombre de su autor: Jorge Luis Borges. También es de Borges un prólogo, que junto con otros breves textos suyos sobre Kafka, ha tenido gran fortuna.

La conclusión obligatoria es que aquella traducción del año 25, tan notablemente precoz, es de Borges y con ello todo misterio se ha vuelto, al parecer, súbitamente cristalino. ¿Quién otro que Borges podía ser aquella antena extraordinariamente perspicaz que se había adelantado a la recepción crítica de las culturas metropolitanas más refinadas y más abiertas a lo nuevo?

Durante algunas décadas la autoría de la traducción de La metamorfosis (y los otros dos textos) publicada por la Revista de Occidente e incluida en el volumen de Losada no fue cuestionada. Por lo pronto la editorial Losada, agotada la edición de 1938, la republicó en 1943 en una colección más económica de la que hizo a lo largo de más de treinta años incontables reimpresiones. En todas ellas Borges figura como traductor de todos los textos incluidos. Cuando en 1960 Losada cede el derecho de esa traducción para las Obras Completas de Kafka publicadas por la editorial Emecé, en éstas figura Borges como el traductor de La metamorfosis, de Un artista del hambre y de Un artista del trapecio.

En 1975, Héctor Galmés publicó en Montevideo una nueva traducción de La metamorfosis y en su prefacio se refirió respetuosamente a la de Borges sin dudar de su autoría, pero señaló un cierto número de infidelidades, de errores, e incluso, de

\footnotetext{
${ }^{32}$ Valery Larbaud, “Lettre à deux amis”, en Commerce, Paris, n 2, Autumn 1924.
} 
criterios discutibles, como por ejemplo la división que hace la traducción de Borges de los largos párrafos del original, división que objeta. (De paso digamos que, en general, los errores que señala Galmés son efectivamente tales, aunque sobre uno de ellos volveremos después. Por otra parte, como ocurre siempre, la pulcra traducción de Galmés también incurre en algún error trivial). ${ }^{33}$

Todavía en 1979 Oscar Caeiro, en un trabajo sobre la recepción de Kafka en lengua española -realizado para el excelente Kafka-Lexicon-, con el mero auxilio del principio de identidad, concluyó que el autor de las traducciones de Kafka publicadas en Revista de Occidente durante los años 1925, 1927 y 1932, que ya mencionamos, son de la autoría de Borges. Pero no sólo llegó a esa conclusión sino que la reforzó indirectamente con su reconocimiento de la calidad de la traducción, a la que alaba porque en ella una exacta comprensión del original logra incorporarse con exactitud borgiana en la versión española. ${ }^{34}$

En 1984 en la ya mencionada publicación del Centre George Pompidou, al pie de una reproducción de la tapa de la Revista de Occidente de junio de 1925, número que contiene la primera parte de La metamorfosis, se lee: "la première traduction espágnole de La métamorphose (parfois attribuée, sans preuves, a Jorge Luis Borges $[\ldots])$ ". ${ }^{35}$ En realidad, se trata de lo contrario. De lo que no tenemos pruebas es de que no sea de Borges una traducción publicada como de Borges, con su autorización, y reeditada incansablemente por una editorial responsable. Y nada dice contra ello el hecho de que se haya publicado por primera vez en forma anónima. ¿Es que hay algún motivo para dudar?

Por lo pronto los hubo desde que, en 1974, Fernando Sorrentino -el primer incrédulo que puso en duda la autoría de la traducción- publicó sus conversaciones con Borges en las que este reconoce no ser el autor. ${ }^{36}$ Pero la duda mayor es suscitada por el propio texto. Alcanza una rápida inspección para descubrir que ese texto

${ }^{33}$ Un ejemplo de mera distracción: Galmés traduce erróneamente la frase “Aber es war eben die Ungewissheit, welche die anderen bedrängte und ihr Benehmen entschuldigte”, por "Era precisamente la incertidumbre lo que apremiaba a los otros a disculparlo por su conducta”, cuando el que disculpa a los otros, a causa de que ignoran, es Gregorio Samsa (Franz Kafka. La metamorfosis. Montevideo: Ediciones de la Banda Oriental, 1975, p. 28).

34 "Seine Ubertragungen zeugen von einem sehr genauen Verstandniss des Original, aber auch von grossen Bemuhen, es ganz dem Spanischen zu integrieren, mit einer Treffsicherheit, wie sie bisher nur Borges erreichte” (en Harmut Binder (ed.). Kafka-Handbuch. Sttutgart: A. Kröner, 1979, tomo II, p. 705).

${ }^{35}$ Le siècle de Kafka, op. cit. p.138.

${ }^{36}$ Fernando Sorrentino. Siete conversaciones con Borges. Buenos Aires: El Ateneo, 1996 (Nueva edición con notas actualizadas). Ver también el artículo del mismo autor " $\mathrm{La}$ metamorfosis que Borges jamás tradujo”, La Nación, Buenos Aires, 9 de marzo de 1997, republicado con variantes en Espéculo, Madrid, $\mathrm{n}^{\circ} 10$, Universidad Complutense de Madrid. 
no tiene nada de borgiano y mucho menos del Borges de los años veinte. Vale la pena transcribir algunos ejemplos característicos de la prosa que campea en Inquisiciones, recopilación de 1925. Pero como no es fácil elegir un párrafo ejemplar, porque todos los del libro podrían servir de ejemplo, me limito a trascribir dos. En primer lugar el que estrena el libro: "La prefación es aquel rato del libro en el que el autor es menos autor. Es ya casi un leyente y goza de los derechos de tal: alejamiento, sorna y elogio. La prefación está en la entrada del libro, pero su tiempo es de postdata y es como un descartarse de los pliegos y un decirles adiós”. Y también transcribo este otro con el que se cierra el mismo libro:

Con este brusco empellón lírico doy fin a las apuntaciones presentes, encomendando a algún estudiantón de mal humor, buenos odios, breve inventiva y voluntad berroqueña la escritura de un libro que podría intitularse «Hospicio de Palabras Desahuciadas». Para compaginarlo basta enristrar en orden alfabético todas las palabras que ha escrito en el decurso de su vida Rafael Lasso de la Vega y remacharles notas puntiagudas. ${ }^{37}$

Si para inquietarse no bastara con el cotejo de la prosa casi invisible de la traducción, con el lenguaje efectivamente puntiagudo de este Borges juvenil, todavía existe otro fuerte motivo: el texto abunda en expresiones que resultan extrañas a un rioplatense que no podrá dejar de oírlas como hispanismos peninsulares. Anoto algunas en las primeras páginas: "ha poco", "rebullicio", "no había estado malo", "harto mejor”, "dolorcillo”, “coger”, "duro con”, “el accidente de por la mañana”, etc. Cuando descubrí esto, hace ya muchas décadas, quedé convencido de que Borges no era el autor de la traducción que nos ocupa.

En 1980 Losada publicó el primero de los dos volúmenes en los cuales reúne los relatos completos de Kafka, es decir la obra narrativa con exclusión de sus tres novelas más extensas. Aunque se hizo una traducción nueva de todos esos textos, que abarcan en los dos tomos un total de unas 500 páginas, se siguen usando las traducciones que aparecieron en Revista de Occidente y son las únicas que se sigue atribuyendo a Borges. ${ }^{38}$ Pero ahora ocurre una leve modificación del texto que aparece expurgado de todos los hispanismos, como si se buscara evitar que exhiba algún signo que pueda hacer dudar de la veracidad de la atribución. Que esa operación no fue hecha con la colaboración de Borges, y seguramente tampoco con su conocimiento, se puede inferir del hecho de que el autor de las correcciones no solamente cambió a veces una expresión marcadamente hispánica por otra más usual en el Río de la Plata, sino que intentó algún cambio mayor. En algunos casos

\footnotetext{
${ }^{37}$ Inquisiciones, op. cit., pp. 5 y 159.

${ }^{38}$ Franz Kafka. Relatos completos (2 vols.). Buenos Aires: Losada, 1981.
} 
es claro que no se consultó el texto alemán y que la modificación aleja la versión española del original sin que con ello se gane nada. Por ejemplo, en la traducción de Revista de Occidente y en la de Losada (de 1938 y siguientes) "und Ihm diesen Amblick und Lärm zu ersparen" se traslada por "y de ahorrarle el tormento de aquel espectáculo y de aquel jollín”. Frente al vocablo "jollín”, el corrector que quiso argentinizar el texto -seguramente después de recurrir al diccionario para enterarse de qué quería decir esa palabra- la sustituyó por "alboroto"; pero no lo suficientemente contento agregó: "que en un momento se había desencadenado" ${ }^{39}$ Con lo cual, al innecesario término "tormento" que había introducido Borges o quien fuese, esta nueva mano anónima sumó una nueva infidelidad. No hay duda de que Borges no tuvo nada que ver con eso.

Todo esto me llevó a reiterar a Borges la pregunta que le había hecho Sorrentino unos años antes, pero de cuya respuesta pocos parecían haberse enterado. Alrededor de 1981, le pregunté a Borges en Buenos Aires por la autoría de esa traducción. El diálogo fue algo extraño porque durante algunos minutos Borges evitó responder la pregunta y derivó sobre otros temas acerca de los cuales ya antes había dicho lo mismo, en particular sobre la inadecuación de la expresión "metamorfosis" para traladar Verwandlung, puesto que en alemán se dispone del término de origen griego y también del término germánico, y que la elección de Kafka podía ser respetada en español en tanto disponemos también del término "transformación". (Desde luego que me abstuve de opinar sobre el punto, aunque podía haberle recordado que el término metamorfosis tiene en alemán un uso casi exclusivamente científico, y que Kafka lo tenía vedado porque titular con él ese relato le hubiera dado en alemán un acento diferente del que tiene ese título en español). Me explicó que se mantuvo el título, a pesar de su desacuerdo, por la insistencia del editor en aplicar el mismo criterio que siguieron las traducciones francesa e inglesa, olvidando que la española era anterior y llevaba ese título. El otro desvío para no responder directamente a mi pregunta tuvo que ver con su conocimiento temprano de Kafka y de la literatura alemana de vanguardia a través de la suscripción a publicaciones expresionistas en sus tiempos juveniles de Suiza. Sólo cuando insistí me contestó, algo alterado, que la traducción de La metamorfosis no era suya, y sí en cambio la de los otros breves relatos incluidos en el libro de 1938 tantas veces reeditado. Y no me atreví a preguntarle, dada la molestia que le causaba el asunto, por qué razones había amparado con su nombre el conjunto de las traducciones incluidas en el libro y cómo a lo largo de tantos años había dejado correr ese malentendido.

Esa confesión fue hecha con evidente disgusto en un diálogo que no tenía el carácter de un reportaje sino de una conversación privada. Y no fue reiterada, en cambio, poco tiempo después en un texto, que ya mencioné, que transcribe palabras

${ }^{39}$ Op. cit., T. I, p. 115. 
de Borges a propósito de Kafka en ocasión del centenario del nacimiento de este. En la oportunidad, Borges eludió ostensiblemente la cuestión y se limitó a declarar lo siguiente:

yo traduje un libro de cuentos para Losada y ellos le pusieron de título La metamorfosis. Ahora, yo no quise porque el título alemán es "Die Verwandlung", que quiere decir "la transformación”, y por algo Kafka eligió esa palabra... Había que traducirla así, y no como se hizo aquí, que recuerda a Ovidio, en fin... "Verwandlung" es una palabra alemana y "metamorfosis" es una palabra griega. De cualquier forma, tampoco La metamorfosis es lo mejor de él. ${ }^{40}$

Lo notable de todo este párrafo es la forma de decir indirectamente que no es el autor de la traducción. Como lo hizo en el diálogo conmigo, Borges desplazó el tema de la traducción al de la adecuación del título en español. Podríamos decir que esta es una forma metonímica de desvincularse de la traducción del todo mediante el expediente de exhibir su disconformidad con la traducción de la parte. Pero Borges introdujo todavía otras formas indirectas de decir que no es el traductor. Después de afirmar, en el pasaje que mencionamos antes, que descubrió a Kafka en 1917, agrega que varios años más tarde leyó sus novelas y sus cuentos, lo que excluye que haya leído, y por lo tanto traducido, La metamorfosis en 1925. Aún más, al referirse a la nouvelle de Kafka, se distancia de ella, y también indirectamente de la responsabilidad de haberla elegido, al señalar que no es parte de la obra más valiosa del autor. ¿Por qué esas cautelas o esas vacilaciones cuando bastante tiempo antes Sorrentino había ya publicado sus declaraciones terminantes: "yo no soy el autor de la traducción. Para simplificar -quizá por razones meramente tipográficas- se prefirió atribuirme a mí la traducción de todo el volumen, y se usó una traducción anónima que andaba por ahí”. ${ }^{41}$

En este punto podríamos dar el asunto por cerrado. Mi antigua convicción de que Borges no es el autor de la traducción a él atribuida, estaría confirmada. And yet... and yet...

Por lo pronto quedaría por explicar tanto que Borges haya aceptado aparecer como el autor de una traducción ajena cuanto que haya sido tan reticente en reconocer la falsedad de la atribución y tan inconvincente en las razones que dio para explicarla. Y algo más aún, puesto que si no es explicable la docilidad generosa de Borges en el sentido de cargar con la responsabilidad de una traducción ajena y dorarla con el brillo de su autoría, todavía lo es menos el que haya asumido (olvidémonos, para verlo a esta luz, de que estamos hablando de Borges) la apropiación

${ }^{40}$ Clarín, Buenos Aires, art. cit.

${ }^{41}$ F. Sorrentino, op. cit., p. 138. 
de un trabajo ajeno. Es cierto que se puede explicar la excesiva generosidad de prestar su nombre como una simple negligencia, y la reticencia en admitir esto como un acto de cobardía ante el duro trance de la confesión. Parecería que si atribuimos a Borges estas dos debilidades tan comunes, podríamos dar cuenta de las dificultades. Creo, sin embargo, que todavía no tenemos derecho a quedar satisfechos y no solamente porque tengamos la necesidad de exculpar a Borges de estos pecados más o menos veniales, sino porque aún nos quedan varios cabos sueltos.

En primer lugar, el hecho de que no está en juego solamente La metamorfosis. Como vimos, en la edición de Losada se atribuye también a Borges la traducción de los otros dos textos publicados en Revista de Occidente. Esos textos tienen las mismas características del de La metamorfosis: su estilo nada tiene que ver con el de Borges y, para un rioplatense, su lenguaje resulta claramente peninsular. Y esto cambia en alguna medida los datos del problema. En primer lugar porque en las dos ocasiones ya mencionadas en que Borges reconoció que no era autor de la traducción cuestionada no se refirió para nada a estos dos textos, más aun afirmó indirectamente en su conversación conmigo ser el autor de ellos. Y además, y sobre todo, porque, si excluimos también estos dos textos, lo que resta en la edición de Losada como traducido por Borges no suma más que unas pocas páginas que representan menos de la sexta parte del libro. Es absolutamente increíble que el editor lo presionara para que se hiciera cargo ilegítimamente de cinco sextas partes de la traducción, y parece un chiste de Borges que explique ese hecho como una simplificación tipográfica. Y resulta más increíble, todavía, que Borges haya podido aceptar esa apropiación de una trabajo ajeno al que ni siquiera revisa y respecto del cual carga con todas sus posibles falencias. Y tampoco puede aceptarse la hipótesis de que el motivo fuese el interés del editor por especular con el nombre del traductor, ya que en 1938 no tenía, por cierto, un nombre capaz de asegurar amplias ventas en tanto autor y menos como traductor de ningún libro. Por otra parte, el director de la colección en la que se editó el libro en 1938, Guillermo de Torre, era cuñado de Borges y en absoluto puede haber pasado distraídamente sobre el asunto de la traducción del primer número de esa colección. En ese sentido es interesante comprobar que cuando de Torre publica en la misma colección, el mismo año 1938, tres relatos de Werfel bajo el título de uno de ellos indica quién es el traductor ${ }^{42} \mathrm{y}$, lo que es más significativo, muchos años después en su Historia de las literaturas de vanguardia, nos informa en una nota que esos textos habían sido previamente publicados en Revista de Occidente y luego publicados en forma de libro por la

${ }^{42}$ Franz Werfel. La muerte del pequeño burgués. Buenos Aires. Losada, 1938. (Traducción del alemán de Luis de Vivar). 
editorial Losada, es decir exactamente lo mismo que ocurrió con La metamorfosis. ${ }^{43}$ Por otra parte, en la misma colección y el mismo año publica Gas, de Kayser, también con el nombre del mismo traductor. ¿Podía, de Torre, ignorar que Borges no era el traductor del relato de Kafka? ¿ Y si esta no era obra de Borges, apenas trece años después de la primera publicación, podía tener dificultades insalvables para averiguar la autoría de esa traducción?

En segundo lugar, debemos tener en cuenta varias cosas que ya vimos antes: la importancia de la traducción de Revista de Occidente en tanto fue anterior a ninguna otra y su reconocido efecto sobre Michaux; los vínculos de este autor directos o indirectos con un grupo de escritores rioplatenses al que pertenece Borges; el conocimiento y la curiosidad que Borges tenía ya antes de 1925 respecto de la certeza de la obra de Kafka. De todo ello podemos concluir, casi con certeza, que aun si esa traducción no es suya, de todos modos tiene que haberla leído y probablemente comentado, tanto si conocía el texto original cuanto si aún no lo había leído. Lo cierto es que no se puede entender que se refiera años después a esa traducción-que ofreció con extraordinaria perspicacia una primicia absoluta fuera de la lengua alemana milagrosamente sintonizada con lo que Borges tanto admiraría luego- en términos de "una traducción anónima que andaba por ahí”. Y mucho menos se puede entender que Borges asumiera la autoría ilegítima de una versión que fue, seguramente, el primer contacto con Kafka de un cierto número de escritores rioplatenses, e incluso franceses, que eran sus amigos. No puedo menos de insistir, además, en que su manera de enfrentar la cuestión, las veces que fue obligado a hablar de ella, parece traslucir siempre una incomodidad que no cesa ni siquiera cuando niega ser el autor de la traducción. Cuando en un texto ya citado parecería que aflora subrepticiamente esa negativa, la impresión final es que sólo busca que se mantenga el enigma. Y creo que es necesario considerar como una especie de complicidad con Borges el silencio absoluto que mantiene sobre esta cuestión Rodríguez Monegal, quien estuvo en contacto frecuente con su maestro del que era devoto, y que no puede haber dejado de hurgar, dada su vocación por la información minuciosa, en una cuestión menor pero desconcertante. Incluso, creo que la errónea afirmación de que en su época juvenil en Suiza, Borges no conocía a Kafka y sólo lo leyó en los años treinta, es un esfuerzo -malogrado por las declaraciones posteriores del propio Borges- en el sentido de descargar a este de la responsabilidad de la traducción discutida y a la vez no verse obligado a negar explícitamente que Borges es su autor.

Si atendemos a estas razones no creo que una hipótesis que sea congruente con todos los hechos pueda desvincular a Borges del texto de Revista de Occidente. Por

${ }^{43}$ Guillermo de Torre. Historia de las literaturas de vanguardia. Madrid, Guadarrama: 1974, Tomo I, p. 210 ( $3^{\mathrm{a}}$ ed.). 
el contrario, tiene que vincularlo de tal manera que en 1938 pudiera ser natural para el editor Gonzalo Losada y para de Torre atribuirle esa traducción, y para él mismo aceptar eso.

No tengo una hipótesis en la que verdaderamente pueda creer que cumpla con esa condición. Pero hay una que, sea o no creíble, logra de maravillas coincidir con todos los datos del problema. Hipótesis que tiene, además, su propio encanto borgiano, porque juega con la idea de la fraudulenta intromisión de la ficción en la realidad que en "Tlön, Uqbar, Orbis Tertius" se manifiesta desde la aparición de la Anglo-American Cyclopedia, -que sólo incluye cierta información en algunos ejemplares- ${ }^{44}$ y que, en tantos cuentos borgianos, incluso en el que acabo de mencionar, consiste no solamente en relatar esas fraudulentas intrusiones de la ficción en la realidad, sino también en cometer la también fraudulenta pero inversa intrusión de la realidad en sus propias ficciones, al introducir personajes y lugares próximos al autor, como si ellos fueran valedores y testigos del carácter documental o biográfico de la narración.

El núcleo de esta hipótesis consiste en suponer que Borges, en 1925, decidió hacer realmente una traducción fiel de La metamorfosis; y extrajo de esa premisa las consecuencias obligadas. Una traducción fiel no podría ser sino una traducción en la cual el lenguaje tuviera la simplicidad y la precisa transparencia de la escritura de Kafka, esa prosa sobria, en un alemán muy cuidadoso pero nada solemne, y hasta, a veces, algo familiar. Esa escritura que impresionó a Borges en su primera lectura de un texto de Kafka como una escritura "muy tranquila". 45

$\mathrm{Y}$ aquí debo dar un breve rodeo porque mi argumento comporta algunos supuestos acerca del estilo de Kafka y, también por lo tanto, acerca de su vínculo o su distancia respecto del expresionismo.

Debo advertir que no poseo suficiente competencia como para hablar con fundamento sobre los aspectos puramente lingüísticos de la obra de Kafka. Lo que acabo de indicar aquí se funda, en gran medida, en afirmaciones ajenas. En especial, en lo que dice Klaus Wagenbach sobre el alemán de Praga en general y el de Kafka

${ }^{44}$ La Anglo-American Cyclopaedia no es una invención de Borges. Se trata de la AngloAmerican Encyclopedia, que también, como la del cuento, es en parte una reimpresión de la Encyclopedia Britannica. La Anglo-American Encyclopedia se vendió en América Latina con variantes. El tomo que dedica a cada país está constituido en gran medida por un diccionario biográfico de personajes locales que pagaban su inclusión en él o a los que su inclusión volvía compradores seguros de la obra. Como se ve, no sólo el nombre inspiró a Borges, sino también el hecho, que el cuento capitaliza, de que era una enciclopedia con material fantasmal que podía encontrarse en ciertos ejemplares pero no en otros. Ya indiqué hace tiempo, en otro trabajo, esta borgiana transfiguración en metafísica de las astucias comerciales de una editorial.

${ }^{45}$ Clarín, Buenos Aires, art. cit. 
en particular. ${ }^{46} \mathrm{~A}$ partir de esas observaciones puede interpretarse la actitud lingüística de Kafka como una doble resistencia: una resistencia tanto a la pobreza del alemán de Praga como al tratamiento "artístico" y artificioso de ese indigente que la literatura praguense de lengua alemana intentaba embellecer. Aunque recuerdo, en contradicción parcial con esa opinión, una referencia incidental de Kokoshka, menos despectiva, respecto del alemán praguense al que califica de antiguo y correcto. ${ }^{47}$ Este tema colinda, a su vez, con otra cuestión muy discutida, la de la relación de Kafka con el expresionismo. Sólo quiero recordar las opiniones de Borges que se reiteran en diversos textos referidos a Kafka y según las cuales este no tiene nada de expresionista. En la postura contraria hay una vasta literatura crítica de la que voy a mencionar solamente como ejemplos extremos a Muschg, para quien "Kafka encarna todos los elementos fructíferos del expresionismo de una manera tan significativa y cabal, que tal vez su figura sea erigida en el símbolo histórico del movimiento todo", ${ }^{48}$ y a Sokel, para quien La metamorfosis es la cumbre del expresionismo. ${ }^{49}$ Una posición matizada, pero que, al fin de cuentas, admite la vinculación de Kafka con el expresionismo, es la que sostiene el más conocido especialista de ese movimiento, Paul Raabe. ${ }^{50}$ Steiner reconoce en Kafka solamente un momento inicial expresionista. ${ }^{51}$ Y Kayser, al pasar, admite, a la vez, una continuidad y una ruptura de Kafka con sus contemporáneos. ${ }^{52}$

Por mi parte, pienso que el problema requiere distinguir diferentes niveles. Creo que Kafka tiene una fuerte deuda con el clima literario que el expresionismo configuró en esos años en la literatura alemana como también que su obra se diferencia notablemente de la de los autores expresionistas típicos, y posee algunos rasgos francamente opuestos a los que caracterizan sus obras. Las conocidas observaciones de Borges sobre esas diferencias son indiscutibles. Por otra parte, aunque admitamos que sin ese ambiente expresionista Kafka hubiera podido, de todos modos, escribir como lo hizo - cosa de la que no estoy seguro-, lo que me parece fuera de toda duda es que sin ese ambiente su escritura no hubiese tenido la recepción inicial,

${ }^{46}$ Klaus Wagenbach. La juventud de Kafka. Caracas: Monte Ávila, 1969, pp. 87-96 [1958].

${ }^{47}$ Oskar Kokoshka. Mi vida. Barcelona: Tusquets, 1988, p. 228 [1971].

${ }^{48}$ Walter Muschg. Expresionismo, literatura y panfleto. Madrid: Guadarrama, 1976, p. 160.

${ }^{49}$ Walter H. Sokel, “The Writer in Extremis: Expressionism”, en Twentieth-Century Literature. Stanford: Stanford University Press, 1959, pp. 45-48.

${ }^{50}$ Paul Raabe, "Franz Kafka und der Expressionismus”, en Zeitschrift für deutsche Philologie, 1967, II, p. 161 y ss.

${ }^{51}$ George Steiner. Lenguaje y silencio. Barcelona: Gedisa, 1982, p. 162 [1976].

${ }^{52}$ Wolfgang Kayser. Lo grotesco. Buenos Aires: Nova, 1964, p. 175. 
al fin de cuentas positiva, sin la cual se hubiese retardado o atenuado la explosión de celebridad póstuma que su obra obtuvo pocos años después.

Ahora bien, el Borges de los primeros años veinte no solamente tenía interés en el expresionismo y participaba del nacimiento de la vanguardia de lengua española, sino que lo hacía, entre otras cosas, mediante una operación lingüística que estaba en las antípodas de la que Kafka había emprendido unos años antes. Ya puse algún ejemplo de la escritura del Borges de 1925.

Solamente podríamos suponer que emprendiese la operación de traducir La metamorfosis a contrapelo de su propio estilo, si es que eso para Borges significaba algo así como una purificación o un exorcismo. Pero lo importante es comprender que sólo si era capaz de una operación de esa naturaleza podía obtener una traducción con alguna pretensión de fidelidad. Una operación heroica de fidelidad a contrapelo de sí mismo debía pasar necesariamente por dos cernidores. Uno de ellos debía impedir el paso al lenguaje inventado y lleno de compadradas que Borges cultivaba entonces. Y otro debía dejar en el cedazo todos los rasgos locales de su lengua, so pena de producir en un lector no rioplatense un efecto exótico, a mil leguas, por lo tanto, del que produce la escritura de Kafka. Que se colasen cualquiera de esos rasgos que era necesario filtrar, impondría al lenguaje de Kafka una radical desnaturalización. Y no cabe duda que las anónimas traducciones de Kafka publicadas por Revista de Occidente corren sin estridencias, con una marcada neutralidad idiomática y con una andadura que no exhibe ningún virtuosismo. Las fallas de traducción no son un argumento para repudiarlas como no borgianas, ya que no existe la infalibilidad en el oficio de la traducción y también hay errores en alguna de las traducciones admitidas como propias por Borges.

Al fin de cuentas podemos preguntarnos mediante una interrogación sofística pero tentadora: ¿quién podría mejor despojarse de todo énfasis, virtuosismo y prosa artística? ¿el joven Borges, del que sabemos que se volverá el "otro Borges”, o un anónimo español del que nada sabemos?

El Borges maduro defiende y practica cierta teoría de la traducción que ha estudiado muy bien Efraín Kristal, ${ }^{53}$ pero que sería anacrónico trasponer a su actitud de los años veinte. Sin embargo una aplicación de la idea de que una traducción puede mejorar el original ya puede encontrarse, aunque apenas insinuada, en su traducción de la última página del Ulysses, que se publica el mismo año que la traducción de La metamorfosis. En esta se manifiestan, a la vez, la libertad y el respeto con los que Borges emprende la tarea de traducir: una gran libertad para no quedar atado a la letra, y el respeto al texto en tanto se trata de conseguir, sobre el lector al que se apunta, el más logrado efecto que el texto original pretendía obtener. De este modo

${ }^{53}$ Efraín Kristal. Borges y la traducción. Manuscrito. Debo el conocimiento de este texto a Pablo Rocca, a quien se lo proporcionó su autor en 1999. 
en una traducción dirigida a un público rioplatense se acriolla no solamente el lenguaje (el uso del voseo rioplatense, por ejemplo) sino también los referentes que permiten anclar el texto en un cierto mundo. Es así que "fine cattle" se vuelve simplemente "ganado", los "fields of oats" se vuelven "maizales", desaparecen los "rododendros", "Mr. Stanhope and Mr. Hester" se reducen a "fulano y zutano", y de igual modo en muchos otros casos. Pero lo interesante es que, además, Borges modifica el texto, aunque sea de un modo muy leve, para volverlo más consistente con su tono dominante. Me parece claro que Borges intenta que el monólogo interior lo sea no sólo por su falta de puntuación y por sus asociaciones libres, es decir por su fluencia y por su contenido, sino también íntimo por su estofa lingüística. Y en ese sentido se aparta muchas veces de la traducción literal con el propósito de preservar la espontaneidad de ese discurso cada vez que, por ejemplo, traduce "old captain” por “capitán” y "old windows” por "ventanas”, o cada vez que introduce aumentativos o diminutivos que subjetivan y coloquializan el discurso como cuando "poor donkeys" pasa a ser "pobres burritos" o "queer little streets” pasa a ser "callecitas rarísimas". ${ }^{4}$

De la traducción de La metamorfosis, suponiendo que es de un argentino, se podría decir que trata de conservar el efecto original sobre el lector español utilizando un lenguaje que este sienta como propio, y, que, a la vez, sea tan "manso" como el del texto alemán; y, por otra parte, que se permite alguna libertad con la que el traductor siente que no traiciona sino que fortalece el texto original. Lo interesante es que eso coincide con la estrategia del traductor de la traducción que estamos indagando: también él se permite alguna curiosa libertad.

Quiero aducir, en ese sentido, un argumento cuya fuerza es quizá solamente subjetiva. Galmés señala un error de traducción que no es explicable. La traducción de Revista de Occidente transforma, en cierto pasaje, el resplandor de las lámparas eléctricas de la calle en el reflejo del tranvía eléctrico que pasa. Pero no hay manera de malentender el sustantivo "strassenlampen" del original, ni es fácil explicar como una simple distracción la evocación de un efecto tan peculiar y tan precisamente indicado. Creo que hubo en el traductor la voluntad de alterar el original; solamente esa voluntad explica el aparente error. Y si fue un acto voluntario es la única huella personal de cierto peso que me ha sido posible detectar en esa traducción. Tiendo a pensar que el traductor alteró el texto porque esos reflejos que llegan de la calle le evocan un efecto que le resulta memorable -como me resulta a mí mismo- y que quizá está asociado, como es mi caso, a una experiencia de la infan-

${ }^{54}$ En un debate sobre esta traducción realizado hace varios años en Buenos Aires, Enrique Pezzoni discrepó enfáticamente con el criterio de Borges de "mimetizar en un nivel de lengua coloquial -es decir, realista- el lenguaje de Molly”. Ver Sitio, Buenos Aires, $\mathrm{n}^{\circ}$ 2, $\mathrm{s} / \mathrm{f}$. 
cia. Me refiero al momento en el cual un niño miedoso que no puede dormir, es confortado fugazmente por la luz pasajera que proyecta desde fuera un tranvía. Y creo que ese es un recuerdo muy rioplatense. Por lo menos debe ser un recuerdo propio de quien en los primeros años del siglo era un niño medroso y vivía en una ciudad con tranvías. Seguramente había muchas ciudades con tranvías allá por el Novecientos y muchos niños con miedos nocturnos. Pero pocos candidatos a traducir La metamorfosis en 1925 que hubieran vivido veinte años antes su infancia en una ciudad de lengua española, en que la noche estuviese poblada de tranvías. Y vale la pena recordar que si bien había muchas ciudades con tranvías, en Buenos Aires estos tenían una abundante presencia. Creo que no es inoportuna la siguiente cita del Baedecker de la República Argentina, publicado cuando Borges tenía ocho años: "Buenos Aires les tramways ont pris un grand développement et sont si bien organisés qu'ils ont valu a la ville le surnom de «ville des Tramways»". ${ }^{55}$

Sé que no prueba nada invocar textos como los que voy a mencionar a continuación, pero de todos modos no resisto la tentación de hacerlo. Se trata de algunas referencias en la obra de Borges de los años veinte en las que los tranvías son evocados repetidamente. Podemos quizá no hacer caso de un poema de 1921 en el cual domina la imagen ultraísta ("con el fusil al hombro los tranvías / patrullan las avenidas"), ${ }^{56}$ pero hay otros que trasuntan un clima en el que los tranvías aparecen como viejos habitantes de la memoria. Esto ocurre sobre todo en dos poemas de Luna de enfrente, libro publicado el mismo año en que aparece la traducción de $L a$ metamorfosis. En uno de ellos hay dos versos que dicen: "los tranvías lejanos me ayudan la tristeza / con esa queja larga que sueltan en las tardes”, ${ }^{57}$ y con razón podemos pensar que poco tiene que ver esa genérica tristeza suburbana con aquella luz fugaz que el ignoto traductor atribuyó, traicionando el texto, al paso de un tranvía. Pero hay otro poema del mismo libro que Borges no volvió a incluir ni en la reedición que hizo de Luna de enfrente dentro de su recopilación de poesías de $1943 \mathrm{ni}$, desde luego, en la de las Obras completas de 1974. En ese poema leemos: "Igual que una linterna, bamboleándose y hueco,/ un Lacroze rezonga la cualquier bocacalle./ Su luz rayó las piedras”. ${ }^{58}$ Es innegable que se trata de una imagen que

${ }^{55}$ Baedeker de la Republique Argentine, Barcelona, 1907, p.115.

${ }^{56}$ Jorge Luis Borges, “Tranvías”, en Textos recobrados, op. cit., p. 92.

57 Son los dos versos finales de Dulcia linquimus arva, en Luna de enfrente. Buenos Aires: Ed. Proa, 1925, p. 26. Esos dos versos se conservan intactos en la edición de Poemas de 1943 y en la de Obras completas de 1974. En la edición de 1943 la única modificación que sufre el poema es que no utiliza la mayúscula al comienzo de cada verso como lo hace la edición original de 1925. En cambio en la edición de 1974 el poema muestra muchos cambios y supresiones.

58 "Villa Alvear", en Luna de enfrente, op. cit, p. 40. Sólo aparece en esta primera edición. 
correspondería muy bien al repertorio imaginario del traductor que se atrevió a transformar los simples faroles de la calle en luces que proyecta el tranvía a su paso. Y para volver más persuasiva la hipótesis de un recuerdo de infancia, podemos representarnos aquel momento en el que el paso del tranvía, mientras no llega el sueño, es bienvenido como un oportuno compañero. Esa es una experiencia de la que quizá Borges no se apartó nunca. Cuenta María Esther Vázquez que en cierto momento Borges y su madre se mudaron a un apartamento de Las Heras y Pueyrredón, donde el tránsito de los tranvías ruidosos, según Borges, “eran una compañía en las noches insomnes". ${ }^{9}$

Quizá un recuerdo de infancia es la única firma que Borges dejó escondida en ese texto. Pero ¿̇por qué negar luego la autoría del mismo? Borges no pudo negar la autoría de Inquisiciones, ni la de los otros libros en prosa de los años veinte, solamente pudo perseguirlos y exterminarlos. Pero negó repetidas veces algunas de sus traducciones y también algún otro de sus trabajos. ${ }^{60} \mathrm{Y}$ pudo, quizá, negar la autoría de una traducción en la que realizaba con el lenguaje una operación que es exactamente la inversa de la que hacía en aquellos libros juveniles repudiados. Negarlo era importante no en 1938, en que a nadie le interesaba mucho esta historia, pero sí en 1980, cuando el tema de su escritura ficticia podría dar tanto motivo para desvariar a críticos y profesores de todo el mundo. Muchas veces Borges habló de su temor de ser un impostor (de soñarlo, o de sus sospechas de serlo). Asumiendo la autoría de esa traducción Borges habría mostrado su estofa de impostor, su ilimitada capacidad mímica de disfrazar su estilo, que es casi la confesión de que su propio estilo es una ficción. No asumiendo la autoría, la impostura se vuelve, apenas, una vulgar apropiación ocasional de un bien yacente.

Paradójicamente los píos editores que creyeron borgizar el texto sustituyendo hispanismos por argentinismos, realizaron la impostura absolutamente inversa, es decir la impostura increíble, condenada al fracaso. Transformaron el texto en una traducción que nunca podría ser del Borges de 1925. Ni de un Borges que publicaba su difícil prosa en esa época ni de un hipotético Borges impostor que redactaba ese texto en una lengua blanca suficientemente hispanizada.

\footnotetext{
${ }^{59}$ María Esther Vázquez. Borges, esplendor y derrota. Barcelona: Tusquets, 1996, p. 115.

${ }^{60}$ Según cuenta Rodríguez Monegal (op. cit., p. 268), alguna vez Borges le dijo que la Antología clásica de la literatura argentina que compilaron Pedro Henríquez Ureña y Borges era obra solamente del primero. De igual modo en su Autobiographical Notes atribuyó a su madre las traducciones que hizo del inglés. Y en las conversaciones con di Giovanni no las niega, pero calumnia sus traducciones de los poetas expresionistas y de Joyce, llamándolas “miserable failure” (ver Th. Di Giovanni, D. Halpern y F. MacShane (eds.). Borges on Writing. Nueva York: Dutton and Co., 1973, p. 92).
} 
Esta es, de todas las que he podido inventar, la única hipótesis que cuadra con fechas, hechos, textos.

Pero, claro está, es demasiado un pastiche trivial, un juguete hecho "a la manera” de Borges, para ser verdadera. ¿ंO no?

\section{Otro final}

$\mathrm{Al}$ releer estas páginas en una versión bastante más breve -que fue publicada hace varios años en una preedición universitaria de circulación interna- ${ }^{61}$ me pareció oportuno no solamente actualizarlas y complementarlas sino, además, ofrecer otro final para que el lector pueda elegir el que prefiere. O mejor, quedarse con los dos. Creo que solamente los dos finales pueden acercarnos a la verdad porque el primer final nos dice algo insoslayable: que solamente con Borges es posible aventurar un juego como el que intentan realizar las páginas anteriores. Y por lo tanto también nos dice que ese juego no es una pura invención cuya gracia está en que sustituye a la realidad, sino que si tiene alguna gracia es que nos ayuda a percibirla.

Pero también es claro que, escondido detrás del juego, me abstengo de dar un testimonio objetivo como el que debería consignar bajo juramento ante un notario o un juez. Para lectores a los cuales ese testimonio es indispensable, agrego este segundo final.

Confesémoslo de inmediato: no creo que Borges sea el autor de la bendita traducción. Pero en tanto que la hipótesis, que podemos llamar fantástica, permite un alegato en el que coinciden bastante bien textos, hechos y fechas, de manera que si se tratara de un puzzle podríamos considerar que ha quedado armado, no ocurre lo mismo cuando se trata de justificar la creencia escéptica, valga el oxímoron.

Lo más fuerte que puedo argumentar es que no es posible endilgarle a Borges algunas frases de la traducción que son de una infelicidad irredimible. Elijo una: "Pero la incertidumbre en que se hallaban respecto a él era precisamente lo que aguijoneaba a los otros disculpando su actitud”. Es una frase incorrecta e incomprensible, además de comportar un error de traducción, en el que, como vimos, también incurre Galmés. Es claro que también podría invocar ese ejemplo para defender la tesis de que Borges es el autor de la traducción. Alcanzaría sostener que Borges, además de estar dispuesto a hispanizar su traducción, hacía gala, ya en ese momento, de la capacidad de caricaturizar hasta el grotesco que luego mostraría en sus colaboraciones con Bioy, y que hacía también un primer ensayo de ese ensañamiento con el lenguaje de los españoles que manifestaría luego en sus páginas peleadoras sobre Américo Castro. Pero ya el carácter lúdico de la argumentación habría excedido los límites de la decencia.

${ }^{61}$ Publicación interna de la Facultad de Humanidades y Ciencias de la Educación, Universidad de la República. Montevideo, 1995. 
Creo, por lo tanto, que la tesis que al fin de cuentas acepto, la que afirma que la traducción ha sido erróneamente atribuida a Borges con la aceptación, por lo menos tácita, de este, durante muchos años, solamente puede sostenerse con argumentos débiles y prosaicos que requieren algunos supuestos dudosos o inverificables. Podemos acudir apenas a esas pocas frases torpes del texto, a las dificultades de comunicación a que dio lugar la Guerra civil española, a la negligencia de Guillermo de Torre, muy difícil por cierto de explicar, y a cierta irresponsabilidad algo traviesa de Borges, de la que sí tenemos algunas pruebas.

Las dificultades de comunicación entre Buenos Aires y Madrid en el año 1938 eran altas, y si de Torre ignoraba quién era el traductor probablemente no estaba en condiciones de averiguarlo. No es explicable, desde luego, por qué no tomó el partido de hacer explícita la responsabilidad de la traducción de los textos que estuvieron a cargo Borges en tanto se mantenía anónima la de La metamorfosis y la de los otros dos relatos breves. Quizá Guillermo de Torre, en el primer libro de una colección que tenía una especial calidad gráfica, encuadernada en cartonné, y que publicaba textos poco conocidos y en cierto modo "exquisitos", no quiso publicar traducciones anónimas. Pongo a consideración del lector, pero descarto, que de Torre supiese el nombre del traductor y se negara a publicarlo por ser el de algún connotado franquista.

En lo que atañe a Borges es muy conocido el juego a las escondidas con sus responsabilidades literarias contaminadas de obligación laboral remunerada. En particular eso es manifiesto, como ya lo hemos visto, respecto de las traducciones cuya autoría ha negado o ha diluido -reconociendo que fue apenas un trabajo compartidoo ha autocriticado impiadosamente. Por otra parte nunca reivindicó las traducciones que efectivamente hizo de Kafka -además de las que, en el libro de 1938, sin duda le pertenecen- con lo cual, quizá, pensaba que, cargando con la traducción ajena e ignorando algunas de las propias, equilibraba la balanza de la ciega justicia. De paso aprovecho la oportunidad para indicar aquí, creo que por primera vez, los textos de Kafka que no hay duda que Borges tradujo además de aquéllos de la edición de Losada que efectivamente le pertenecen. He podido detectar por lo menos cuatro textos dispersos en diversas publicaciones. El más antiguo es Ante la ley divulgado inicialmente en El Hogar y republicado por Rodríguez Monegal en Marcha, de Montevideo, unos años después. ${ }^{62}$ Un segundo, Josefina la cantora apareció en 1940 en la Antología de la literatura fantástica, que Borges hizo en colaboración con Bioy y Silvina Ocampo.$^{63}$ El tercero, Las sirenas, fue publicado

${ }^{62}$ Ante la ley fue publicado en El Hogar, Buenos Aires, el 27 de mayo de 1938, el mismo año en que se publica La Metamorfosis en la colección que Guillermo de Torre dirigía en la editorial Losada.

63 Josefina la cantora o el pueblo de los ratones, en Antología de la literatura fantástica, J. L. Borges, S. Ocampo y A. Bioy Casares. Buenos Aires, Sudamericana, 1940, pp. 142- 
en Los Anales de Buenos Aires, que Borges dirigía, junto con otro texto muy breve titulado La verdad sobre Sancho Panza. ${ }^{64}$

Pero esa actitud desprolija no es solamente reconocible en lo que hace a sus traducciones. Aunque no hay duda del extremo rigor de su trabajo puramente creativo sabemos de algunas zonas, en particular las de muchas de sus declaraciones en las cuales la arbitrariedad y la ligereza de Borges ha sido tal que solamente le ha podido ser excusada por el valor irritativo que tiene toda provocación. Menos conocido es el poco cuidado con el que cumplió algunas tareas, incluso en el terreno editorial. Voy a poner un ejemplo que es muy significativo y que corresponde a un momento en el cual la producción editorial argentina, asistida por algunos escritores, críticos y universitarios competentes, realizaron una obra destacable que se ha agrandado y se ha vuelto añorable desde la situación actual del mundo editorial en el Río de la Plata. En ese momento en que esa nueva política editorial intentaba erradicar las ediciones incompletas y adulteradas, que eran tan frecuentes pocos años antes en América y España, Borges tuvo a su cargo la dirección, junto con Bioy Casares, de una colección de la editorial Emecé en la que se publicó una traducción de The Three Impostors, de Arthur Machen. En esa edición falta un capítulo completo de la obra que, aunque más no fuera por su título, The Decorative Imagination, no puede haber escapado a la atención de Borges. ${ }^{65}$

En resumidas cuentas creo que, sicologizando de un modo trivial como suelen hacerlo los biógrafos de Borges, podemos decir que cierto espíritu infractor, que aparece tantas veces en sus juicios, guio también muchos de sus actos y que en determinadas circunstancias podía considerar como una diablura amputar un capítulo a un libro editado bajo su consejo o dar lustre con su nombre a una mediocre traducción de la que no era autor. En todo caso podemos lamentarnos de que no haya realizado, en este caso, la diablura contraria: la de hacer una traducción tal que, después de muchas décadas de credulidades, malentendidos y desconciertos, todos termináramos por afirmar que plagió una traducción ajena.

156. En algún momento tuve noticia de que Xul Solar había traducido esta narración y supuse que podía ser el responsable del texto publicado en esta antología. Luego tuve oportunidad de ver el manuscrito de Xul y comprobé que no se trata de la misma traducción.

${ }^{64}$ El silencio de las sirenas y La verdad sobre Sancho Panza fueron publicados en Los Anales de Buenos Aires, $\mathrm{N}^{\circ} 6$.

${ }^{65}$ Los tres impostores, Arthur Machen. Buenos Aires, Emecé, 1947. (Trad. de Benjamín Openhayn. Colección La Puerta de Marfil, dirigida por Jorge Luis Borges y Adolfo Bioy Casares. El capítulo que falta, titulado The Decorative Imagination, ocupa las páginas 141151 de The Caerleon Edition of the Works of Arthur Machen, Vol. II, The Three Impostors, London, Martin Secker, 1928). 